Published in final edited form as:

Semin Colon Rectal Surg. 2017 June ; 28(2): 86-90. doi:10.1053/j.scrs.2017.04.006.

\title{
Topical therapies for the treatment of anal high-grade squamous intraepithelial lesions
}

\author{
Christina Megill, PA-C and \\ Division of Infectious Diseases, Weill Cornell Medicine 53 W. $23^{\text {rd }}$ St. $6^{\text {th }}$ Floor, New York, NY \\ 10010, 212-746-7204 (phone), 212-746-7203 (fax) \\ Timothy Wilkin, M.D., MPH [Associate Professor of Medicine] \\ Division of Infectious Diseases, Weill Cornell Medicine 53 W. $23^{\text {rd }}$ St. $6^{\text {th }}$ Floor, New York, NY \\ 10010, 212-746-7204 (phone), 212-746-7203 (fax)
}

\begin{abstract}
Anal cancer may be prevented by treating anal high-grade squamous intraepithelial lesions (HSIL). Ablative therapies are the most commonly used treatments, but they may not be appropriate for all patients including those with extensive HSIL or bleeding diastheses.

Researchers have studied topical therapies for human papillomavirus related lesions including anal HSIL. These therapies include patient-applied 5-fluorouracil, imiquimod and cidofovir, and provider-applied trichloroacetic acid. This review will discuss literature supporting efficacy of these products, which is based mainly on case series with few controlled trials having been conducted. Side effects are common with patient-applied topical therapy often requiring dose reduction and medication to treat pain. However, treatment discontinuations are infrequent. This review will also discuss some approaches to the use of these products in clinical practice.
\end{abstract}

\section{Keywords}

Imiquimod; Fluorouracil; Cidofovir; Trichloroacetic acid; Anal dysplasia

\section{Introduction}

Anal cancer is preceded by high-grade intraepithelial lesions (HSIL) and causally linked to persistent infection with high-risk or oncogenic strains of human papillomavirus (HPV). The rates of anal cancer are markedly elevated in HIV-infected people, particularly men who have sex with men ${ }^{1}$. Anal HSIL is found in up to $50 \%$ of HIV-infected men and $25 \%$ of HIV-infected women ${ }^{2,3}$. Treating anal HSIL has been proposed as a strategy for reducing rates of anal cancer in HIV-infected adults and a randomized clinical trial is underway that will test this hypothesis.

Publisher's Disclaimer: This is a PDF file of an unedited manuscript that has been accepted for publication. As a service to our customers we are providing this early version of the manuscript. The manuscript will undergo copyediting, typesetting, and review of the resulting proof before it is published in its final citable form. Please note that during the production process errors may be discovered which could affect the content, and all legal disclaimers that apply to the journal pertain. 
The most commonly used treatments for anal HSIL are ablative procedures such as hyfrecation/fulguration and infrared coagulation. These treatments are typically performed in the office setting. These procedures are effective, but may require multiple treatments and have potential post-procedure complications. Infrared coagulation can eliminate a given lesion $64-81 \%$ of the time, but anal HSIL may develop at other untreated sites in up to $70 \%$ of patients ${ }^{4-6}$. Ablation may be inappropriate for patients with extensive or circumferential disease, and may be inappropriate for patients receiving anticoagulants or with bleeding diatheses. Treatment of anal HSIL in HIV-infected adults is difficult as anal HSIL in this group is more extensive and responds less well to ablative therapy as compared to HIVuninfected groups ${ }^{7}$.

Topical therapies are an alternative approach to ablative treatments. There are no FDAapproved topical therapies for anal HSIL, but based on similarities between the pathophysiology of other genital squamous cell intraepithelial lesions and anal HSIL, patient-applied imiquimod, 5-fluorouracil, and cidofovir have been used for topical treatment of peri-anal and intra-anal HSIL. Provider-applied trichloroacetic acid is also a viable treatment option. There are few controlled clinical trials to determine efficacy of treatments and fewer studies that compare treatment modalities. The current approach to treatment of anal HSIL using topical therapy is informed mainly by case series, small nonrandomized trials and inference from studies of other HPV-associated lesions. (Table 1) This review will discuss existing data and possible uses for these treatments.

\section{5-fluorouracil (5FU)}

Topical treatment with 5-fluorouracil (5FU) was first reported in 1962 for treatment of skin cancers following a report that systemic $5 \mathrm{FU}$ induced regression of keratosis ${ }^{8}$. $5 \mathrm{FU}$ is a pyrimidine analog made by fluorination of uracil on position 5 of the pyrimidine ring. Its principle mechanism of action is to inhibit DNA synthesis by blocking the conversion of uracil deoxyribonucleotide to thymine deoxyribonucleotide ${ }^{9}$. This conversion creates a thymine deficiency resulting in a DNA deficiency, thus leading to disordered function that results in the inability of cells to replicate. A secondary effect of 5FU is direct interference with RNA synthesis and function, inhibiting the incorporation of uracil into RNA by competing with uracil-active enzymes. 5FU's most marked affect is on rapidly proliferating tissues and is commercially available as 1,2, and 5\% 5FU topical cream or gel. The most commonly used concentration for treatment of anal HSIL is 5\%. It causes erythema and edema followed by erosion, ulceration and necrosis when applied topically to a neoplasm. It has been shown to preferentially treat neoplasms with only an inflammatory response on adjacent healthy skin.

Topical 5FU has been used since the1970s to treat female lower genital tract disease caused by HPV ${ }^{10-13}$. There are limited data and a few randomized placebo controlled trials evaluating 5FU for genital warts; a Cochrane review suggests that there is evidence for a therapeutic effect against genital warts ${ }^{14}$. A randomized study evaluated $5 \mathrm{FU} 5 \%$ as prophylactic therapy to prevent recurrence of cervical HSIL following loop electro-excision procedure in HIV-infected women ${ }^{11}$. Recurrence of cervical HSIL in the 5FU group was $28 \%$ compared to $47 \%$ in the observation group. 
There are limited reports of 5FU 5\% specifically for treatment of anal lesions. In one study evaluating treatment of patients with perianal HSIL, 7 of 8 patients treated with topical 5FU $5 \%$ cream applied twice weekly for 16 weeks had no evidence of perianal HSIL on followup biopsies at 12 months post-treatment ${ }^{15}$. Richel and colleagues reported an open-label study of 46 HIV-infected patients with intra-anal LSIL or HSIL: multifocal lesions were seen in $76 \%$ and anal HSIL in $74 \%{ }^{16}$. In this study, $1 \mathrm{~g}$ of $5 \mathrm{FU} 5 \%$ was inserted using an applicator twice weekly at night for 16 weeks. Complete responses were seen in 12 of 34 patients with anal HSIL and partial responses with a decrease in HSIL to LSIL were seen in an additional 8 subjects. Thirty-nine participants (85\%) experienced side effects, but only 2 participants discontinued treatment early. Snyder and colleagues reviewed 11 patients using $0.25 \mathrm{~g}$ of $5 \mathrm{FU}$ placed intra-anally at bedtime for a median treatment time of 20 weeks ${ }^{17}$. One patient discontinued therapy due to side effects and $73 \%$ of patients experienced anal pain or irritation. Five of nine patients with HSIL at baseline had improvement in their disease, although 8 of 9 had HSIL on post treatment biopsies.

Jay et al. described the results of a trial from the UCSF Anal Neoplasia Clinic using intraanal 5FU 5\% twice daily for 5 days, followed by a 9 -day rest period ${ }^{18}$. The cycle was repeated 4 times and patients re-evaluated. Twenty patients with extensive anal HSIL involving more than $75 \%$ of the circumference were evaluable. Complete histologic regression was seen in 3 patients, a significant decrease in the volume of disease allowing ablation was observed in 16 patients, and 1 had no response. The side effects included pain, ulceration, bleeding, and exacerbation of herpes simplex. However, only 2 of 27 discontinued treatment because of side effects and 4 were considered non-adherent and not evaluable because they completed less than 2 cycles.

Richel et al. reported on 148 HIV-infected men who have sex with men with squamous intraepithelial lesions (57\% with HSIL) randomized to 4-month treatments with $2 \% 5 \mathrm{FU}$, $5 \%$ imiquimod, or monthly electrocautery ${ }^{19}$. The complete response rate (i.e. no SIL noted on post-treatment biopsy) was $17 \%, 24 \%$, and $39 \%$, respectively in the intention to treat group with severe side effects reported as $27 \%, 43 \%$, and $18 \%$, respectively. Recurrence rates were $58 \%, 71 \%$, and $68 \%$ at 72 weeks post-treatment. In the group with HSIL, the complete or partial response rate was $43 \%, 46 \%$, and $68 \%$ respectively. This is the only report comparing $5 \mathrm{FU}$ to imiquimod in a randomized study.

\section{IMIQUIMOD}

Imiquimod has been used for treatment of external genital warts since 1997. It is an imidazoquinoline amine, which is a topical synthetic compound that upregulates the adaptive and innate immune systems to exert antiviral activity and to treat dysplastic tissue by inducing apoptosis through the intrinsic pathway ${ }^{20}$. The indirect mechanism is binding cell surface receptors resulting in secretion of a variety of inflammatory mediators including interferon alpha, TNF-alpha, IL-12, IL-1, 6, 8, and 10. These cytokines then activate the cell-mediated immune response and in turn the release of interferon-gamma, responsible for activating cytotoxic T-cells and natural killer cells in the local environment ${ }^{21}$. Imiquimod has no direct antiviral activity or direct effect on T-cells but is a strong inducer of Th-1 type 
cytokines resulting in recruitment of dense CD4+ infiltrates, which is an important mechanism for HPV clearance and one that is reduced in HIV-infected populations.

Off-label use of imiquimod is common in both skin and mucosal disease ${ }^{22,23}$ with extensive case reports noted in the medical literature. Imiquimod has been reported for treatment of infectious diseases including molluscum contagiosum, genital herpes and cutaneous leishmaniasis ${ }^{24-26}$ Finally, imiquimod has been used for treatment of vulvar, penile and anal squamous intraepithelial lesions ${ }^{27-31}$.

Imiquimod has demonstrated efficacy for the treatment of anogenital condyloma in a series of randomized clinical trials ${ }^{32}$. Response rates to imiquimod for genital condyloma are better in HIV-negative patients compared to HIV-positive patients, with response rates of $62 \%$ and $31 \%$ respectively ${ }^{32}$. The role of imiquimod in clearing anal HPV infection in patients with anogenital condyloma was investigated in a single arm study involving 239 HIV-infected and -uninfected men and women. At baseline, 95\% had low risk HPV, 60\% had high risk HPV, and 56\% had both. Condyloma were treated with imiquimod 5\% cream for external warts and suppositories for intra-anal disease, three times a week for 26 weeks. At 12 weeks, $30 \%$ of subjects with high-risk HPV had cleared their infection as did $66 \%$ of subjects with low-risk HPV ${ }^{33}$.

There are limited reports describing the efficacy of imiquimod 5\% for treatment of anal HSIL $^{34}$. Imiquimod is also available in $2.5 \%$ and $3.75 \%$ formulation. These formulations have an FDA indication for treatment of actinic keratosis in adults and for treatment of external genital warts $(E G W)^{35}$. In one study, 14 of 19 (74\%) HIV-positive MSM with intraanal and/or perianal LSIL or HSIL had complete regression of SIL after treatment with imiquimod $5 \%^{33}$. Among 13 patients with HSIL at baseline, 9 (69\%) cleared HSIL at the end of treatment. A decrease in in the number of HPV types and HPV viral load was also seen following treatment. Fox et al conducted a randomized, double-blind placebo controlled study of imiquimod 5\% for anal HSIL enrolling 53 patients ${ }^{36}$. Among 28 patients in the imiquimod arm, 4 had complete HSIL resolution and 8 downgraded from HSIL to LSIL. Only 1 subject of 25 in the placebo arm experienced complete resolution of HSIL.

\section{CIDOFOVIR}

Cidofovir is a cytidine nucleotide analogue with activity against a broad spectrum of viruses including herpes viruses, adenoviruses, and $\mathrm{HPV}^{37}$. It is FDA approved for cytomegalovirus retinitis. Cidofovir causes selective inhibition of HPV-infected cell proliferation ${ }^{38}$ and increases the levels of the tumor suppressor protein $\mathrm{p} 53^{39}$. Cidofovir produces a selective cytotoxic effect against HPV-infected cells because they concentrate dephosphorylated cidofovir while normal cells concentrate a different form of cidofovir ${ }^{40}$. Induction of apoptosis causes cell death after successful cidofovir treatment ${ }^{38}$.

Cidofovir has been studied for the treatment of genital and anal condyloma, and anal HSIL. As with the other topical patient-applied treatments the dosing regimens vary widely ${ }^{41-46}$. Cidofovir $1 \%$ in cream or gel was compared to electrocoagulation for the treatment of condyloma in a small study of 20 subjects. The complete or partial response rate was $92 \%$ 
with the use of the $1 \%$ gel versus $55 \%$ with ablation ${ }^{41}$. A large randomized study enrolling HIV-infected patients with genital condyloma compared electrocautery alone, $1 \%$ cidofovir gel alone 5 days a week for up to 6 weeks, and electrocautery followed by cidofovir 5 days a week for 2 weeks initiated 4 weeks after electrocautery. Complete response rates for the three arms were $93 \%, 76 \%$ and $100 \%$, respectively. Recurrence rates were $74 \%, 35 \%$ and $27 \%$, respectively and clearly showed the benefit to cidofovir treatment ${ }^{44}$.

There was a single arm clinical trial enrolling 33 HIV-infected adults with perianal HSIL; 8 female participants had vulvar HSIL as well ${ }^{47}$. All participants self-applied $1 \%$ cidofovir gel to the lesions once daily, leaving it in place for 6-8 hours before washing it off. Treatment continued for 5 days followed by 9 days off. This two-week cycle was repeated 6 times. Twenty-six participants (79\%) completed the treatment course. A complete response was observed in 5 (15\%), partial regression in the extent of HSIL was observed in 12 (36\%), 7 $(21 \%)$ had stable disease, and 2 had progression (1 developed a superficially invasive cancer and 1 developed a new HSIL during 16 weeks of followup). Seventeen patients were enrolled in a pilot clinical trial of $1 \%$ cidofovir 2 grams applied intra anally 3 times a week for 4 weeks ${ }^{48} ; 63 \%$ cleared HSIL when assessed at 12 weeks. The main limitation of cidofovir is that there are no commercial preparations available; the cream or gel must be prepared for individual patients by a compound pharmacist and it might not be covered by standard insurance.

\section{TCA}

Topical trichloroacetic acid (TCA) is recommended by the Center for Disease Control as a first-line therapy for perianal condyloma ${ }^{49}$. TCA is caustic and corrodes the skin and mucous membranes. It treats HSIL by denaturing and precipitating proteins resulting in tissue destruction ${ }^{50}$. TCA is provider-applied in the office setting and has the advantage over other topical treatments of not requiring patient adherence other than repeated office visits for treatments. TCA has not been reported to have any systemic side effects and is well tolerated by patients (see Chart 2). TCA is the only topical treatment that is safe to use in pregnancy 49 .

TCA treatment requires HRA to identify and locate HSIL. Wooden-tipped cotton applicators are used to apply TCA. The cotton end is dipped in the TCA to partially saturate the cotton. The liquid should be absorbed only halfway through the cotton to avoid oversaturation and dripping of TCA. Some providers dip the wooden end of the cotton applicator into the TCA to allow more precise application of the TCA. These applicators are then inserted through the anoscope and guided to the lesions. TCA is applied by touching the applicator to the lesion repeatedly until the area becomes opaque, dense, and snow-white in appearance. Allowing time for drying prevents the acid from spreading to unaffected areas. Four or five applications are typically needed to completely treat the lesion. Treatment concentrations of TCA are not standardized, but the studies reviewed use concentrations of $80-85 \% 51,52$. Only very small amounts of TCA should be in the procedural field and it should be properly labeled to avoid being mistaken for acetic acid or other liquids. 
Multiple treatment visits are typically required, usually spaced 3-4 weeks apart. A retrospective review of HIV-infected men diagnosed with anal SIL who were treated with TCA in up to 4 separate treatment visits found that $61 \%$ of patients cleared to LSIL or no lesion ${ }^{51}$. Greater clearance was seen among men who were younger in age $(<49$ years) or had 2 or fewer lesions requiring treatment. Another larger retrospective review described men diagnosed with HSIL over a three-year period ${ }^{52}$. This study evaluated outcomes of 98 HSIL lesions 3-6 months after TCA treatment. Patients with areas of disease that extended beyond $25 \%$ of the anal circumference for an individual lesion or beyond $50 \%$ for all lesions were not treated with TCA because of theoretical concern for scarring. Seventy-nine percent of the treated lesions improved to LSIL or resolved to normal epithelium or during the time of follow up. They also found that a single TCA treatment course improved or resolved $49 \%$ of the lesions, with $27.6 \%$ requiring two treatment courses for similar outcomes.

TCA may not be appropriate for treating extensive or bulky disease, but does, however, offers a treatment option for HRA providers not yet able to offer other ablative therapies. TCA is a safe and low cost treatment with fewer adverse events compared to other treatments for HSIL.

\section{Adverse event management}

Adverse events occur commonly during treatment with patient-applied topical therapy. The most common adverse events are pain, irritation, erythema, and ulceration at the site of application. Patients should be advised to avoid exposure to areas without HPV lesions such as perineum, lower vulva or scrotum. Imiquimod may also lead to systemic side effects such as influenza-like symptoms. Although side effects occur in the majority of patients, permanent discontinuation of the treatment course is uncommon. Side effects after provider applied trichloroacetic acid appear to be minimal.

Side effects troublesome to the patient or that interfere with normal activities may be managed using topical analgesics and/or dose modification. There are FDA-approved cream formulations of lidocaine, prilocaine and tetracaine available for intra-anal use. Patients can apply the cream prior to bowel movements and at other times for symptomatic relief. Patients experiencing burning sensation may experience some benefit from warm baths ${ }^{53}$. These strategies are generally successful for milder symptoms. For patients experiencing more significant side effects, dose interruption should be considered until the side effects have lessened in intensity. Treatment can be restarted at a reduced dose. (Table 2) If the patient tolerates the reduced dose, dose escalation to full treatment dose can be considered after a few weeks of the reduced schedule.

\section{Dose application and adherence support}

Patient-applied topical therapy needs to be applied to the site of disease for optimal efficacy. For intra-anal disease, this means applying the cream from the squamocolumnar junction distally to the anal verge. Most patients are able to do this by self-applying the cream using a gloved finger inserted into the anus. Some providers recommend splitting the dose and applying with the left and right hands to ensure complete coverage. If possible, patients should be observed applying a dose in the office. This will identify any challenges for self- 
administration and allow for additional education. There are no specific anal applicators designed for this purpose. If using an applicator or syringe, care must be taken to avoid inserting the cream beyond the anus into the rectum. This will lead to loss of efficacy and may lead to additional side effects such as proctitis.

Patients should be counseled on the importance of sustained adherence and the need to communicate occurrence of side effects that are beyond mild. It may be reassuring for patients to know that side effects may indicate treatment efficacy. Many of the dose schedules are intermittent; calendars or electronic reminders should be offered to remind patients of the dosing schedule. An interim visit within 4 weeks of initiating treatment is advisable to identify unexpected challenges in administration, to survey for side effects and to support adherence.

\section{Acknowledgments}

There was no grant support for this article.

\section{References}

1. Crum-Cianflone N, Hullsiek KH, Marconi V, et al. Trends in the incidence of cancers among HIVinfected persons and the impact of antiretroviral therapy: a 20-year cohort study. AIDS. 2009; 23:41-50. [PubMed: 19050385]

2. Chin-Hong PV, Vittinghoff E, Cranston RD, et al. Age-related prevalence of anal cancer precursors in homosexual men: the EXPLORE study. J Natl Cancer Inst. 2005; 97:896-905. [PubMed: 15956651]

3. Hessol NA, Holly EA, Efird JT, et al. Anal intraepithelial neoplasia in a multisite study of HIVinfected and high-risk HIV-uninfected women. AIDS. 2009; 23:59-70. [PubMed: 19050387]

4. Stier EA, Goldstone SE, Berry JM, et al. Infrared coagulator treatment of high-grade anal dysplasia in HIV-infected individuals: an AIDS malignancy consortium pilot study. J Acquir Immune Defic Syndr. 2008; 47:56-61. [PubMed: 18156992]

5. Goldstone SE, Kawalek AZ, Huyett JW. Infrared coagulator: a useful tool for treating anal squamous intraepithelial lesions. Dis Colon Rectum. 2005; 48:1042-1054. [PubMed: 15868241]

6. Goldstone SE, Hundert JS, Huyett JW. Infrared coagulator ablation of high-grade anal squamous intraepithelial lesions in HIV-negative males who have sex with males. Dis Colon Rectum. 2007; 50:565-575. [PubMed: 17380365]

7. Nathan M, Hickey N, Mayuranathan L, Vowler SL, Singh N. Treatment of anal human papillomavirus-associated disease: a long term outcome study. Int J STD AIDS. 2008; 19:445-449. [PubMed: 18574114]

8. FALKSON G, SCHULZ EJ. Skin changes in patients treated with 5-fluorouracil. Br J Dermatol. 1962; 74:229-236. [PubMed: 13891467]

9. Ceilley RI. Mechanisms of action of topical 5-fluorouracil: review and implications for the treatment of dermatological disorders. J Dermatolog Treat. 2012; 23:83-89. [PubMed: 21034289]

10. Brodman M, Dottino P, Friedman F, Heller D, Bleiweiss I, Sperling R. Human papillomavirusassociated lesions of the vagina and cervix. Treatment with a laser and topical 5-fluorouracil. J Reprod Med. 1992; 37:453-456. [PubMed: 1324311]

11. Maiman M, Watts DH, Andersen J, Clax P, Merino M, Kendall MA. Vaginal 5-fluorouracil for high-grade cervical dysplasia in human immunodeficiency virus infection: a randomized trial. Obstet Gynecol. 1999; 94:954-961. [PubMed: 10576182]

12. Krebs HB. Treatment of vaginal condylomata acuminata by weekly topical application of 5fluorouracil. Obstet Gynecol. 1987; 70:68-71. [PubMed: 3601270]

13. Sillman FH, Sedlis A, Boyce JG. A review of lower genital intraepithelial neoplasia and the use of topical 5-fluorouracil. Obstet Gynecol Surv. 1985; 40:190-220. [PubMed: 2984615] 
14. Batista CS, Atallah AN, Saconato H, da Silva EM. 5-FU for genital warts in nonimmunocompromised individuals. Cochrane Database Syst Rev. 2010:CD006562. [PubMed: 20393949]

15. Graham BD, Jetmore AB, Foote JE, Arnold LK. Topical 5-fluorouracil in the management of extensive anal Bowen's disease: a preferred approach. Dis Colon Rectum. 2005; 48:444-450. [PubMed: 15747068]

16. Richel O, Wieland U, de Vries HJ, et al. Topical 5-fluorouracil treatment of anal intraepithelial neoplasia in human immunodeficiency virus-positive men. Br J Dermatol. 2010; 163:1301-1307. [PubMed: 20716208]

17. Snyder SM, Siekas L, Aboulafia DM. Initial Experience with Topical Fluorouracil for Treatment of HIV-Associated Anal Intraepithelial Neoplasia. J Int Assoc Physicians AIDS Care (Chic). 2011; 10:83-88. [PubMed: 21266323]

18. N, J., T, D., J, P. 25th International Papillomavirus Conference. Malmo, Sweden: 2009. Treatment of diffuse high-grade anal intraepithelial neoplasia with 5\% fluorouracil Cream.

19. Richel O, de Vries HJ, van Noesel CJ, Dijkgraaf MG, Prins JM. Comparison of imiquimod, topical fluorouracil, and electrocautery for the treatment of anal intraepithelial neoplasia in HIV-positive men who have sex with men: an open-label, randomised controlled trial. Lancet Oncol. 2013; 14:346-353. [PubMed: 23499546]

20. Leverkus M. Imiquimod: unexpected killer. J Invest Dermatol. 2004; 122:XV-XVI.

21. Navi D, Huntley A. Imiquimod 5 percent cream and the treatment of cutaneous malignancy. Dermatol Online J. 2004; 10:4.

22. David CV, Nguyen H, Goldenberg G. Imiquimod: a review of off-label clinical applications. J Drugs Dermatol. 2011; 10:1300-1306. [PubMed: 22052312]

23. Grossberg AL, Gaspari AA. Topical antineoplastic agents in the treatment of mucocutaneous diseases. Curr Probl Dermatol. 2011; 40:71-82. [PubMed: 21325841]

24. Hengge UR, Cusini M. Topical immunomodulators for the treatment of external genital warts, cutaneous warts and molluscum contagiosum. Br J Dermatol. 2003; 149(Suppl 66):15-19.

25. Hengge UR, Esser S, Schultewolter T, et al. Self-administered topical 5\% imiquimod for the treatment of common warts and molluscum contagiosum. Br J Dermatol. 2000; 143:1026-1031. [PubMed: 11069514]

26. Gill VL, Bergman PJ, Baer KE, Craft D, Leung C. Use of imiquimod 5\% cream (Aldara) in cats with multicentric squamous cell carcinoma in situ: 12 cases (2002-2005). Vet Comp Oncol. 2008; 6:55-64. [PubMed: 19178663]

27. Mathiesen O, Buus SK, Cramers M. Topical imiquimod can reverse vulvar intraepithelial neoplasia: a randomised, double-blinded study. Gynecol Oncol. 2007; 107:219-222. [PubMed: 17655918]

28. van Seters M, Fons G, van Beurden M. Imiquimod in the treatment of multifocal vulvar intraepithelial neoplasia 2/3. Results of a pilot study. J Reprod Med. 2002; 47:701-705. [PubMed: 12380448]

29. Poluri RM, Higgins SP. Successful treatment of penile Bowen's disease with $5 \%$ imiquimod cream. Int J STD AIDS. 2005; 16:649.

30. Ramoni S, Cusini M, Gaiani F, Arancio L, Alessi E. Penile intraepithelial carcinoma treated with imiquimod 1\% in an HIV-positive patient. J Dermatolog Treat. 2009; 20:177-178. [PubMed: 19016064]

31. Kreuter A, Hochdorfer B, Stücker M, et al. Treatment of anal intraepithelial neoplasia in patients with acquired HIV with imiquimod 5\% cream. J Am Acad Dermatol. 2004; 50:980-981. [PubMed: 15153912]

32. Wagstaff AJ, Perry CM. Topical imiquimod: a review of its use in the management of anogenital warts, actinic keratoses, basal cell carcinoma and other skin lesions. Drugs. 2007; 67:2187-2210. [PubMed: 17927284]

33. Kreuter A, Potthoff A, Brockmeyer NH, et al. Imiquimod leads to a decrease of human papillomavirus DNA and to a sustained clearance of anal intraepithelial neoplasia in HIV-infected men. J Invest Dermatol. 2008; 128:2078-2083. [PubMed: 18273049] 
34. Mahto M, Nathan M, O'Mahony C. More than a decade on: review of the use of imiquimod in lower anogenital intraepithelial neoplasia. Int J STD AIDS. 2010; 21:8-16. [PubMed: 20029061]

35. Medicis. Zyclara package insert. 2017. http://pi.medicis.us/zyclara.pdf

36. Fox PA, Nathan M, Francis N, et al. A double-blind, randomized controlled trial of the use of imiquimod cream for the treatment of anal canal high-grade anal intraepithelial neoplasia in HIVpositive MSM on HAART, with long-term follow-up data including the use of open-label imiquimod. AIDS. 2010; 24:2331-2335. [PubMed: 20729710]

37. Safrin S, Cherrington J, Jaffe HS. Clinical uses of cidofovir. Rev Med Virol. 1997; 7:145-156. [PubMed: 10398479]

38. Andrei G, Snoeck R, Schols D, De Clercq E. Induction of apoptosis by cidofovir in human papillomavirus (HPV)-positive cells. Oncol Res. 2000; 12:397-408. [PubMed: 11697818]

39. Abdulkarim B, Sabri S, Deutsch E, et al. Antiviral agent Cidofovir restores p53 function and enhances the radiosensitivity in HPV-associated cancers. Oncogene. 2002; 21:2334-2346. [PubMed: 11948417]

40. Johnson JA, Gangemi JD. Selective inhibition of human papillomavirus-induced cell proliferation by (S)-1-[3-hydroxy-2-(phosphonylmethoxy)propyl]cytosine. Antimicrob Agents Chemother. 1999; 43:1198-1205. [PubMed: 10223936]

41. Coremans G, Margaritis V, Snoeck R, Wyndaele J, De Clercq E, Geboes K. Topical cidofovir (HPMPC) is an effective adjuvant to surgical treatment of anogenital condylomata acuminata. Dis Colon Rectum. 2003; 46:1103-1108. discussion 1108-1109. [PubMed: 12907906]

42. Snoeck R, Bossens M, Parent D, et al. Phase II double-blind, placebo-controlled study of the safety and efficacy of cidofovir topical gel for the treatment of patients with human papillomavirus infection. Clin Infect Dis. 2001; 33:597-602. [PubMed: 11477525]

43. Matteelli A, Beltrame A, Graifemberghi S, et al. Efficacy and tolerability of topical $1 \%$ cidofovir cream for the treatment of external anogenital warts in HIV-infected persons. Sex Transm Dis. 2001; 28:343-346. [PubMed: 11403192]

44. Orlando G, Fasolo MM, Beretta R, Merli S, Cargnel A. Combined surgery and cidofovir is an effective treatment for genital warts in HIV-infected patients. AIDS. 2002; 16:447-450. [PubMed: 11834957]

45. Orlando G, Fasolo MM, Beretta R, et al. Intralesional or topical cidofovir (HPMPC, VISTIDE) for the treatment of recurrent genital warts in HIV-1-infected patients. AIDS. 1999; 13:1978-1980. [PubMed: 10513659]

46. Stragier I, Snoeck R, De Clercq E, Van Den Oord JJ, Van Ranst M, De Greef H. Local treatment of HPV-induced skin lesions by Cidofovir. J Med Virol. 2002; 67:241-245. [PubMed: 11992585]

47. Stier EA, Goldstone SE, Einstein MH, et al. Safety and efficacy of topical cidofovir to treat highgrade perianal and vulvar intraepithelial neoplasia in HIV-positive men and women. AIDS. 2013; 27:545-551. [PubMed: 23032420]

48. Sendagorta E, Bernardino JI, Álvarez-Gallego M, et al. Topical cidofovir to treat high-grade anal intraepithelial neoplasia in HIV-infected patients: a pilot clinical trial. AIDS. 2016; 30:75-82. [PubMed: 26731755]

49. Workowski KA, Berman SM, Prevention CfDCa. Sexually transmitted diseases treatment guidelines, 2006. MMWR Recomm Rep. 2006; 55:1-94.

50. Wiley DJ, Douglas J, Beutner K, et al. External genital warts: diagnosis, treatment, and prevention. Clin Infect Dis. 2002; 35:S210-224. [PubMed: 12353208]

51. Singh JC, Kuohung V, Palefsky JM. Efficacy of trichloroacetic acid in the treatment of anal intraepithelial neoplasia in HIV-positive and HIV-negative men who have sex with men. J Acquir Immune Defic Syndr. 2009; 52:474-479. [PubMed: 19779306]

52. Cranston RD, Baker JR, Liu Y, Wang L, Elishaev E, Ho KS. Topical application of trichloroacetic acid is efficacious for the treatment of internal anal high-grade squamous intraepithelial lesions in HIV-positive men. Sex Transm Dis. 2014; 41:420-426. [PubMed: 24922100]

53. Gupta PJ. Effects of warm water sitz bath on symptoms in post-anal sphincterotomy in chronic anal fissure-a randomized and controlled study. World J Surg. 2007; 31:1480-1484. [PubMed: 17534541] 
54. van der Snoek EM, den Hollander JC, van der Ende ME. Imiquimod 5\% cream for five consecutive days a week in an HIV-infected observational cohort up to 32 weeks in the treatment of high-grade squamous intraepithelial lesions. Sex Transm Infect. 2015; 91:245-247. [PubMed: 25596191] 


\section{Summary}

There are viable topical treatment options for anal HSIL, and they are appealing for patients with extensive HSIL or patients with contraindications to ablative therapies. Provider-applied trichloroacetic acid appears to have minimal side effects and is a reasonable treatment option for patients with focal HSIL opting for a non-surgical approach. Patient-applied imiquimod and 5FU appear to have efficacy against anal HSIL and are available by prescription, but robust data from randomized clinical trials are lacking. Even if complete resolution of HSIL is not achieved, a reduction in the amount of disease may allow for less extensive ablative treatment of residual disease. These treatments cause frequent side effects and prescription of topical analgesics and/or dose reductions are often needed. However, the vast majority of patients are able to complete treatment courses. Further studies are needed to further define the efficacy of these treatments and their optimal role in the management of anal HSIL 


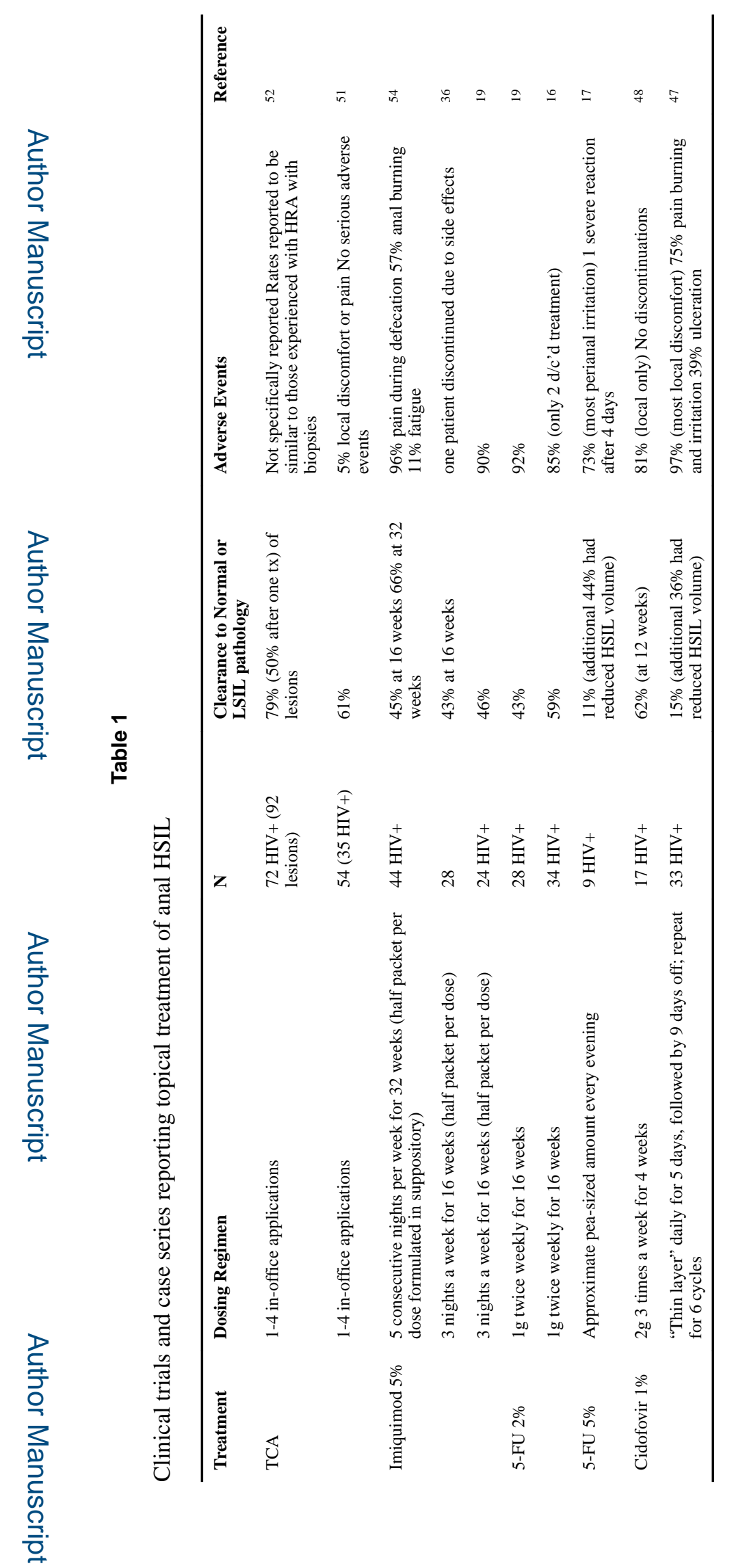

Semin Colon Rectal Surg. Author manuscript; available in PMC 2018 June 13. 
TABLE 2

Dosing of patient-applied topical therapy for anal HSIL

\begin{tabular}{|c|c|c|c|}
\hline & Topical 5-fluorouracil 5\% & Imiquimod $5 \%$ & Cidofovir $1 \%$ \\
\hline Standard dose & $\begin{array}{l}0.5 \mathrm{~mL}(0.5 \mathrm{gm}) \text { applied intra-anally twice daily } \\
\text { for } 5 \text { days followed by } 9 \text { days off }\end{array}$ & $\begin{array}{l}0.5 \text { to } 1 \text { packet applied intra- } \\
\text { anally } 3 \text { times a week at night }\end{array}$ & $\begin{array}{l}1 \mathrm{~mL}(1 \mathrm{gm}) \text { applied intra anally } \\
\text { daily at night for } 5 \text { days followed by } \\
9 \text { days off }\end{array}$ \\
\hline Reduced dose & $\begin{array}{l}0.5 \mathrm{~mL}(0.5 \mathrm{gm}) \text { applied intra-anally twice daily } \\
\text { for } 3 \text { days followed by } 11 \text { days off }\end{array}$ & $\begin{array}{l}0.5 \text { to } 1 \text { packet applied intra } \\
\text { anally } 2 \text { times a week at night }\end{array}$ & $\begin{array}{l}1 \mathrm{~mL}(1 \mathrm{gm}) \text { applied intra anally daily } \\
\text { at night for } 3 \text { days followed by } 11 \\
\text { days off }\end{array}$ \\
\hline Minimal dose & $\begin{array}{l}0.5 \mathrm{~mL}(0.5 \mathrm{gm}) \text { applied intra-anally daily for } 3 \\
\text { days followed by } 11 \text { days off }\end{array}$ & $\begin{array}{l}0.5 \text { to } 1 \text { packet applied intra } \\
\text { anally once a week }\end{array}$ & $\begin{array}{l}0.5 \mathrm{~mL}(0.5 \mathrm{gm}) \text { applied intra anally } \\
\text { daily at night for } 3 \text { days followed by } \\
11 \text { days off }\end{array}$ \\
\hline
\end{tabular}

Note: additional cream may be needed to treat perianal disease. 